\title{
CONF-9507152-5
}

UCRL-JC-120501

PREPRINT

\section{High-Resolution Imaging of Hypervelocity Metal Jets Using Advanced High-Speed Photographic Techniques}

\author{
L. L. Shaw \\ S. A. Muelder
}

This paper was prepared for submittal to the

Proceedings of the 20th International Symposium on Shock Waves

Pasadena, CA

July 23-28, 1995

August 29, 1995

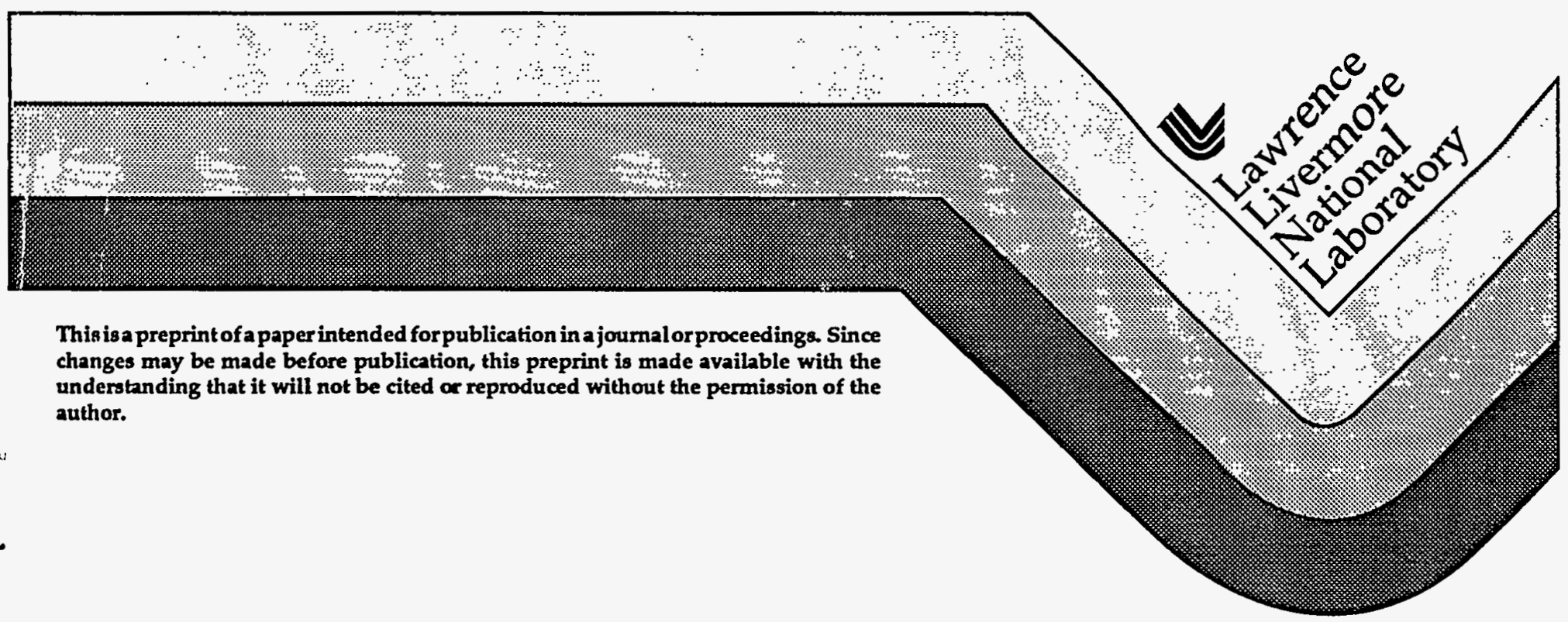




\section{DISCLAIMER}

This document was prepared as an account of work sponsored by an agency of the United States Government. Neither the United States Government nor the University of California nor any of their employees, makes any warranty, express or implied, or assumes any legal liability or responsibility for the accuracy, completeness, or usefulness of any information, apparatus, product, or process disclosed, or represents that its use would not infringe privately owned rights. Reference herein to any specific commercial product, process, or service by trade name, trademark, manufacturer, or otherwise, does not necessarily constitute or imply its endorsement, recommendation, or favoring by the United States Government or the University of California. The views and opinions of authors expressed herein do not necessarily state or reflect those of the United States Government or the University of California, and shall not be used for advertising or product endorsement purposes. 


\section{DISCLAIMER}

Portions of this document may be illegible in electronic image products. Images are produced from the best available original document. 


\title{
High-Resolution Imaging of Hypervelocity Metal Jets Using Advanced High-Speed Photographic Techniques
}

\author{
L. L. Shaw, S. A. Muelder \\ Lawrence Livermore National Laboratory \\ Box 808, L-281, Livermore California 94550, USA
}

\begin{abstract}
It is now possible to obtain high resolution sequential photographs of the initial formation and evolution of hypervelocity metal jets formed by shaped charge devices fired in air. Researchers have been frustrated by the high velocity of the jet material and the luminous sheath of hot gases cloaking the jet that made detailed observation of the jet body extremely difficult. The camera system that provides the photographs is a large format multi-frame electro-optic camera, referred to as an IC camera (IC stands for image converter), that utilizes electro-optic shuttering, monochromatic pulsed laser illumination and bandpass filtering to provide sequential pictures (in 3$\mathrm{D}$ if desired) with minimal degradation due to luminous air shocks or motion blur. The large format ( $75 \mathrm{~mm}$ image plane), short exposure ( $15 \mathrm{~ns}$ minimum), ruby laser illumination and bandpass filtering (monochromatic illumination while excluding extraneous light) produces clear, sharp, images of the detailed surface structure of a metal shaped charge jet during early jet formation, elongation of the jet body, jet tip evolution and subsequent particulation (breakup) of the jet body. By utilizing the new camera system in conjunction with the more traditional rotating mirror high speed cameras, pulsed radiography, and electrical sensors, a maximum amount of, often unique, data can be extracted from a single experiment. This paper was intended primarily as an oral presentation. For purposes of continuity and simplicity in these proceedings, we have chosen to concentrate on the development of the IC camera system and its impact on the photography of high speed shaped charge jets.
\end{abstract}

Key Words: image converter camera, laser illuminated photography, electro-optic shutter, multipulsed ruby laser, high-speed photography, shaped charge jet

\section{Introduction}

High speed photography is a major diagnostic in the study of fast phenomena such as the acceleration and deformation of high explosive driven metal surfaces However, multiple frame high speed photography has been of limited benefit in the study of the jets formed by shaped charge devices fired in air. One problem is poor spatial resolution due to the motion blur caused by the movement of the jet material during the exposure time of the camera frame. A second problem is the shock induced luminosity cloaking the tip and body of the jet that blocks direct observation of the jet surface. In grder to minimize the effect of object motion on picture resolution, exposure times as short as $10^{-8} \mathrm{sec}$ must be possible. To photograph the surface of the jet the camera must "see through" the shock induced luminosity and exclude it from the camera while at the same time photographing an adequately illuminated jet surface. The use of the recently developed multi-frame electro-optic shuttered image converter camera (IC camera) with pulsed ruby laser illumination meets the performance parameters just stated and provides the means to obtain the high resolution sequential photographs of these jets. A nominal 20 nanosecond exposure time greatly reduces the effect of material motion, even for velocities in the range of 10 kilometers per second. The monochromatic 694 nanometer pulsed ruby laser illumination with 1.5 nanometer bandpass filtering allows the self luminosity and other extraneous light to be excluded from the photographs. With this system, sequential pictures of the surface of a metal shaped charge have been obtained that show the detailed metallurgy as the jet proceeds from initial formation through particulation. 


\section{IC Camera system}

The IC camera system described in this paper is a direct outgrowth of the development work in proximity focused image converter tubes and in pulsed solid state lasers that has occurred over the past 40 years. Experimenters and diagnosticians realized that the ultra short exposure time possible using the image converter tube as a shutter permitted the photographing of fast phenomena minimizing motion blur, and a number of framing cameras utilizing these tubes were built. (Chancel 1972; Owren 1959). During the same time period, experimenters realized that the exposure time of mechanical cameras could be dramatically reduced by using pulses from Qswitched or cavity-dumped lasers as light sources. There were also two other attributes of using lasers: extraneous light could be excluded from the camera by the use of bandpass filtering that transmits only the wavelength of the laser light, and the technique proved very adaptable for stereo photography (Carpluk 1970; Paisley 1976). Over the past fifteen years, we have combined the best attributes of the electro-optic framing camera and pulsed laser illumination into a high speed framing photography system (Shaw 1984).

\subsection{IC camera}

The camera has a modular design as shown in Figure 1. Each module is a complete two-frame camera with its own objective optics and mechanical shutter. An internal $50 \%$ mirror creates two image planes from a single entrance optic. Individually triggered $75 \mathrm{~mm}$ diameter proximity focused image converter tubes are positioned at each image plane, and have adjustable exposure times with a minimum of 12 to $15 \mathrm{~ns}$. A detailed description of the camera timing and control system is provided in references Shaw 1984 and Shaw 1993. The optical system consists of a $200 \mathrm{~mm}$ to $1140 \mathrm{~mm}$ zoom lens and a five-to-one magnifying relay lens which transmits and magnifies the image formed by the $35 \mathrm{~mm}$ format objective optics to match the format of the $75 \mathrm{~mm}$ image converter tubes. The standard format of eight frames is made up of four modules originally designed to be clustered on a single hydraulic stand, but it is often more convenient to use just two per stand as shown in Figure 2. The modular construction and this type of mounting introduces approximately 1 degree of parallax between modules, but the result is acceptable and very useful in stereo photography.

The film used in this camera is Kodak T-MAX 32004 X 5 inch sheet film. The speed, resolution, and low fog level of this film have been major factors in the high quality of the photographs taken with this system. The film is routinely developed at ISO 6400 and quite often pushed to ISO 12800. This allows significant leeway in the choice of illumination light levels and in the adjustment of the aperture to manipulate film exposure and the camera depth of field. Extraneous light from air shocks, explosive products, and other sources is prevented from entering the camera by a $1.5 \mathrm{~nm}$ bandpass filter centered at $694 \mathrm{~nm}$ (ruby laser wavelength) and positioned at the output of the objective optics.

\subsection{Eight pulse Ruby laser illuminator.}

The eight pulse Q-switched ruby laser is a novel design that permits the extraction of four separate pulses from a single ruby rod during a single pumping of the rod. This is illustrated in cartoon fashion in Figure 1 and shown in Figure 3. A mask with four 6-mm diameter holes allows each quadrant of a $19 \mathrm{~mm}$ dia. rod to be used in a separate laser cavity. The nominal energy of each pulse is 0.5 joules and is approximately Gaussian with a full width at half maximum of $50 \mathrm{~ns}$. Although this design was developed independently, we quickly discovered the approach had previously been developed by others (Jones 1974). Figure 4 is a graphic example of the IC camera's ability to produce detailed photographs in the presence of intense ambient light by using monochromatic laser illumination coupled with a band-pass filter. 

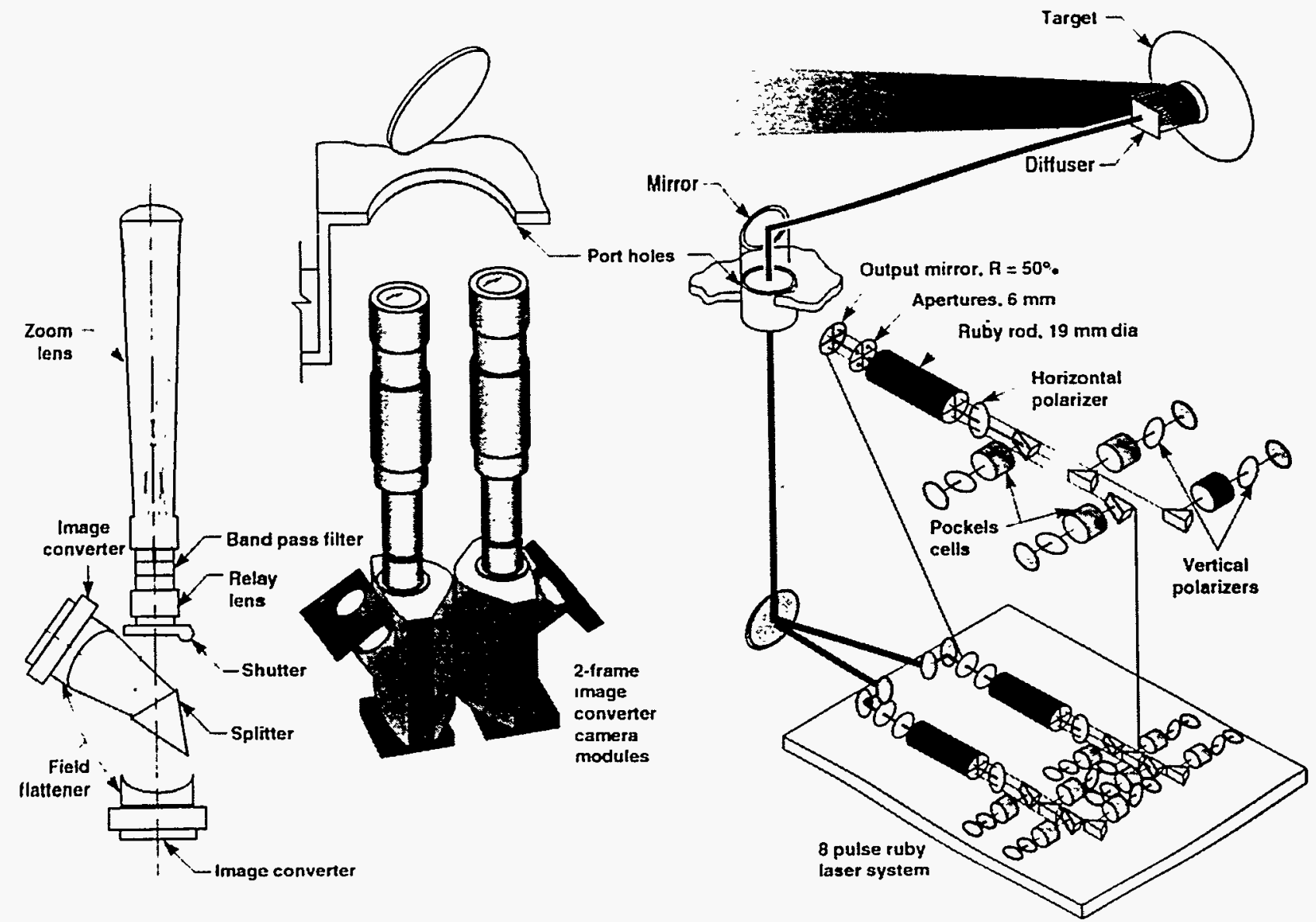

Figure 1. .Diagram of the eight-frame IC (image-converter) camera and the eight-pulse ruby laser illuminator. Note the modular camera construction with two frames per objective optic. The laser is configured to provide four independent pulses from a single rod. Both the camera and the laser are located in a concrete reinforced underground bunker below and to the side of the experimental firing area.

The timing and control system, not addressed in this paper, consists of programmed delays and triggers that initiate the individual image converter tube drivers and the laser Pockels cell drivers. The jitter of this system is less than $5 \mathrm{~ns}$ allowing the 15-20 ns exposure time of each frame to be well centered in the $50 \mathrm{~ns}$ laser illumination pulse reflected from the experiment. Transient digitizers measure laser to camera simultaneity, and reference timing to the main experimental timing.

\section{Experiments}

The illustrations used in this paper are of experiments evaluating the performance of explosive shaped charges. Figure 5(a) is a cartoon of a representative experimental layout. Figure 5(b) is a cross-section view of a typical shaped charge. In diagnosing experiments, we place many diverse diagnostics on the same experiment. These include low energy pulsed radiography, electrical signal pins, and rotating mirror framing and streak cameras. These additional diagnostics have been excluded from this paper but are discussed in some detail in the references (Shaw 1979, Shaw 1993). The IC camera and laser are located in an underground bunker adjacent to and below the level of the gravel test area known as the firing table. Front surface mirrors direct the incident laser beam to the experiment and the reflected laser light to the camera. The laser pulses strike a ground glass diffuser, placed close to the experiment, that scatters the laser light over the experiment. Matte white poster board placed around the experiment provides a light background and helps to "splash" the laser light onto the target. 


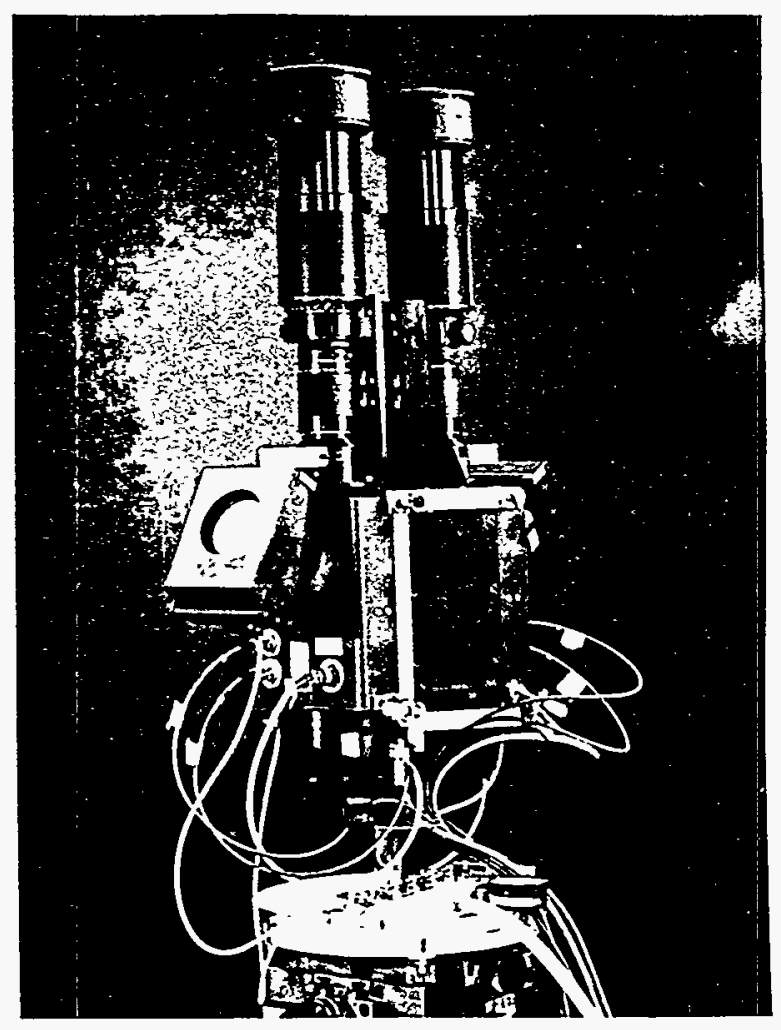

Figure 2. A pair of IC camera modules mounted on a vertical hoist in the firing bunker camera room viewing the experimental firing table through a $30 \mathrm{~cm}$ glass porthole in the camera room ceiling. The $\mathbf{2 0 0 - 1 1 4 0 ~} \mathrm{mm}$ focal length zoom lens on the camera and the magnification of five by the internal relay lens yiclds an image on film up to nearly full size at an object distance of 10 meters. Object details as small as $\mathbf{1 0 0}$ microns can be resolved in the resultant photographs.

Figure 3. The eight-pulse ruby laser system using two ruby rods located in the flashlamp heads seen at the right center of the photograph. Also clearly visible at the lower left are the four white Pockels cells used to Q-switch the four cavities of the nearer ruby rod. The beams from the two ruby rods are brought together and guided to the firing table through the vertical tube just visible at the top of the photograph.

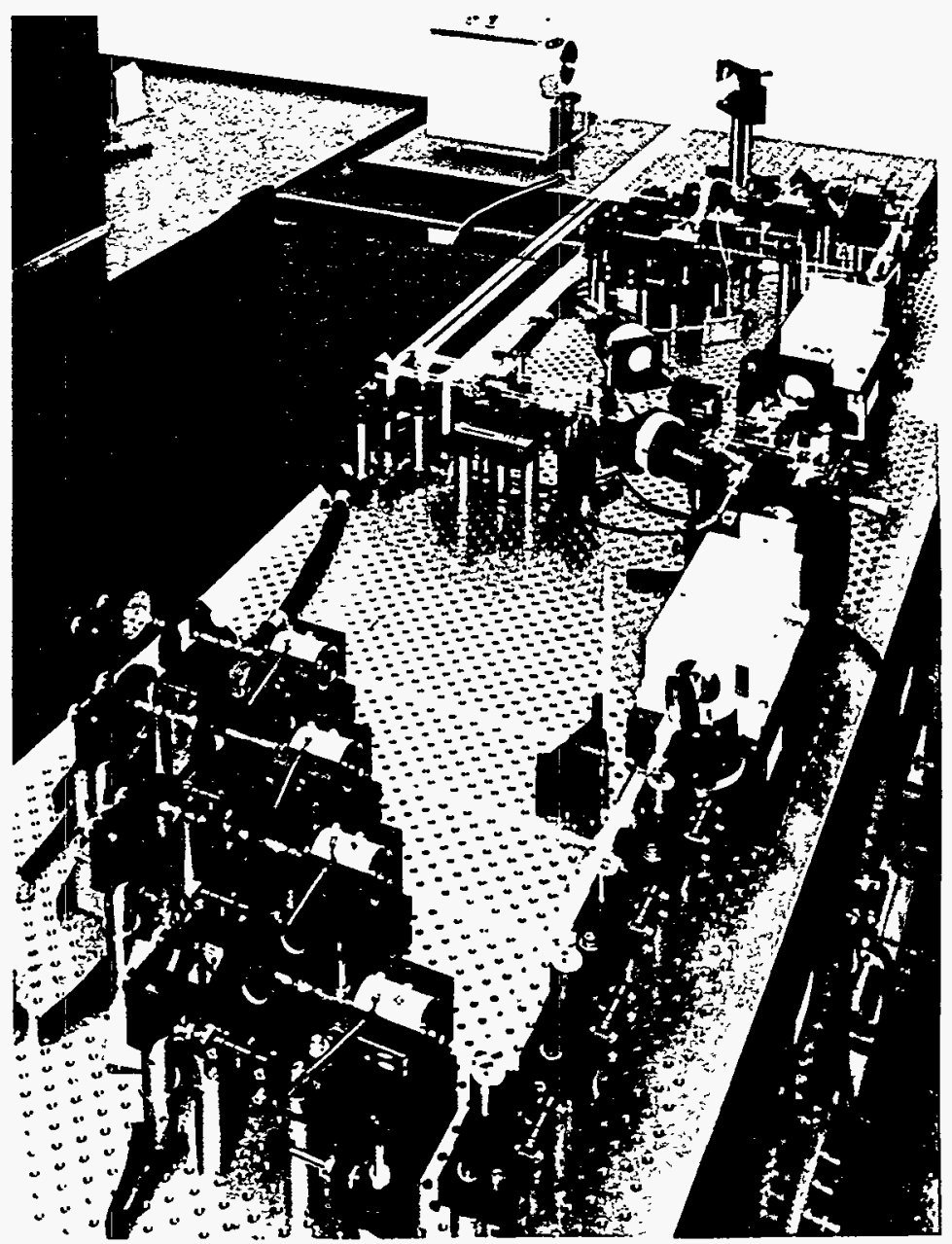


(a)

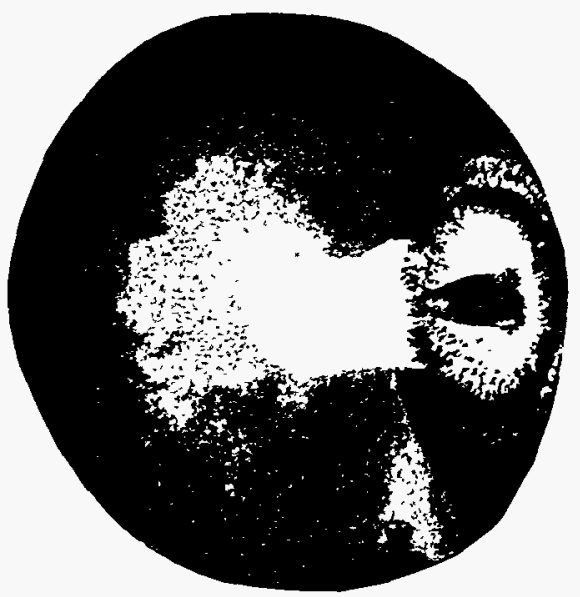

(b)

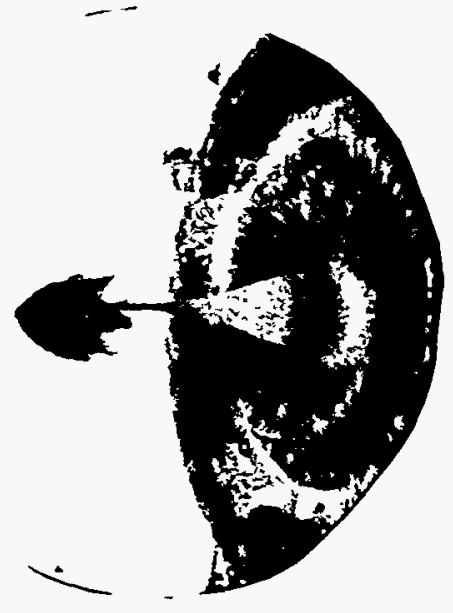

Figure 4. IC camera photographs of a jet from a shaped charge with a hemispherical liner. The two pictures were taken $200 \mathrm{~ns}$ apart on the same experiment using two different camera modules - one module without the $1.5 \mathrm{nM}$ bandpass filter, and one with it. The exposure time for both photographs was $15 \mathrm{~ns}$. In (a), the only illumination is from the luminous air shock surrounding the jet. In (b), the illumination is from the pulsed ruby laser where the bandpass filter excludes the luminour air shock allowing observation of the underlying metal structure.

Figure 5. (a) Diagram of a typical test setup used for shaped-charge experiments. For simplicity, only one IC camera station is shown. Not shown are some of the other dignostics often fielded in these experiments such as rotating mirror framing cameras. (b) Section view of the "Viper" shaped charge used in some of these experiments. The electrically initiated exploding bridge wire on the right end launches a detonation wave through the high explosive. The detonation causes the copper liner to collapse, turn inside out, and "squirt" to the left at velocities approaching $10 \mathrm{~km} / \mathrm{sec}$

(a)

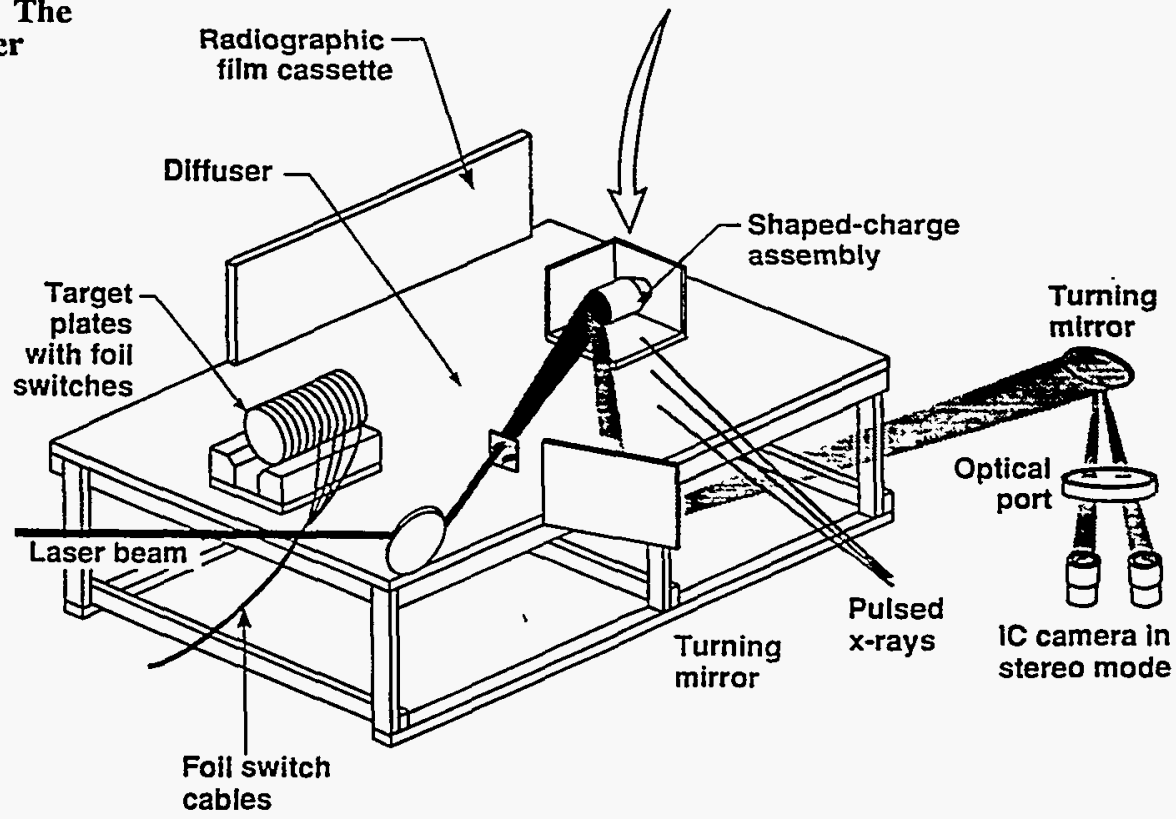

(b)

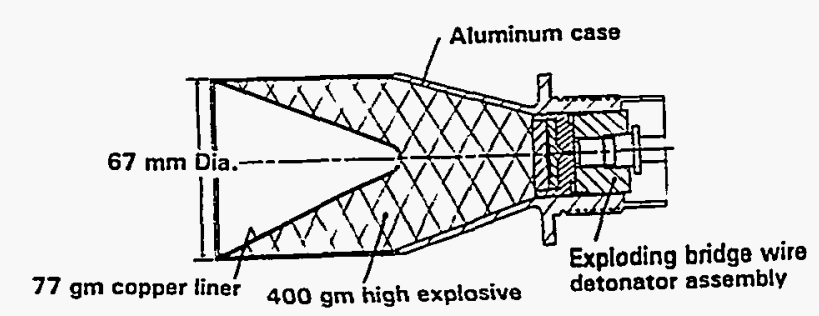

Foil switch 


\section{Results}

In the oral presentation, we discussed photographing the entire evolution of the shaped charge hypervelocity jet. In this proceedings, we have concentrated on the high resolution detail the IC camera is able to record as the metal surface of the jet stretches and cracks during initial elongation and pulls apart into what are eventually discrete pieces as the jet particulates. In Figures 6,7,10, and 11 we have chosen to use IC camera pictures of jets which, while illustrative of the ability to record overall jet characteristics with unique tip structure and air shock formations, were chosen primarily to illustrate the surface characteristics of the elongationg jet.

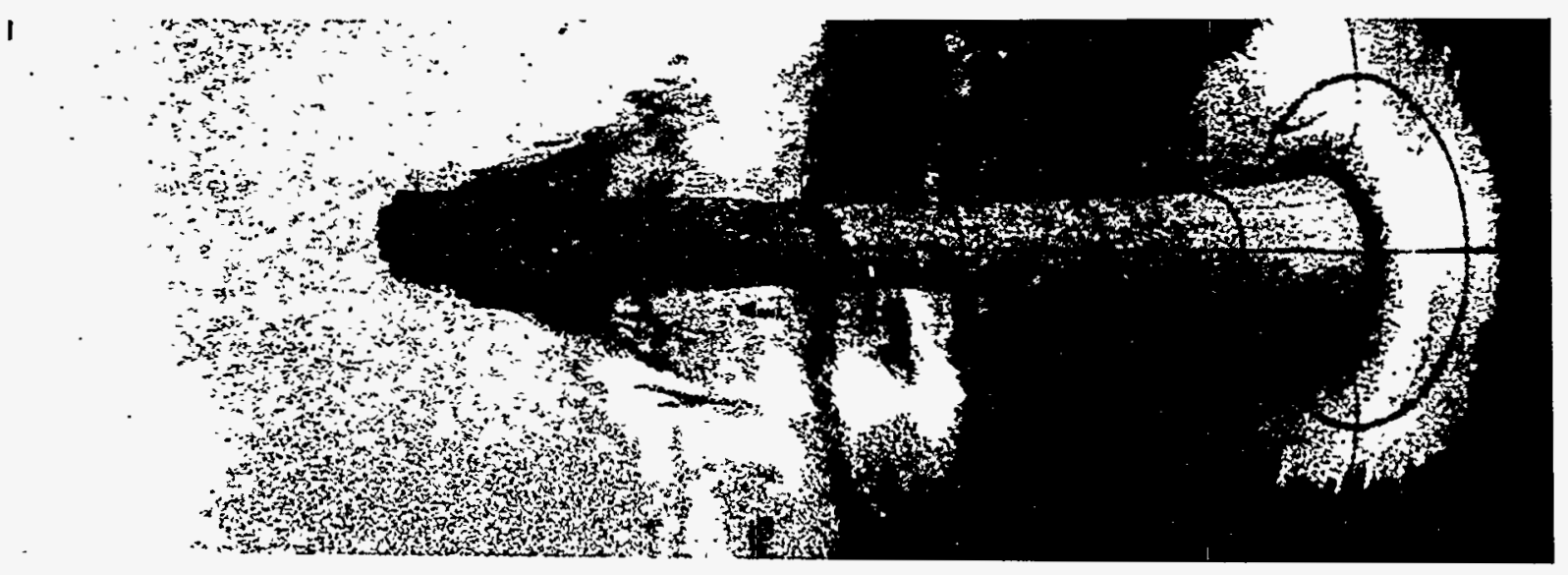

(a)

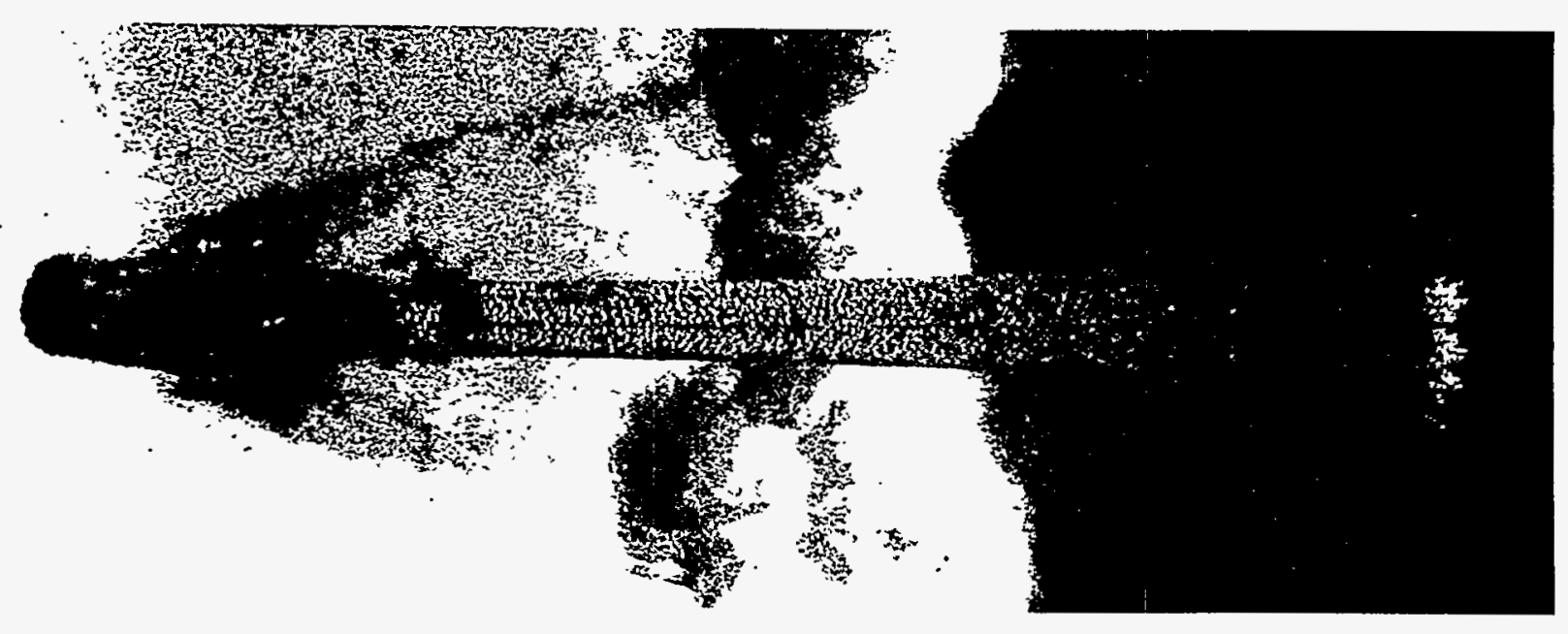

(b)

Figure 6. Laser illuminated photographs of a shaped charge with a conical liner. Grid lines are made with a fine felt-tipped permanent marker on bare metal. The lines thicken and stretch with the liner deformation providing valuable quantitative strain and timing data. (a) 15 nsec exposure taken 40.8 usec after shaped charge detonator initiation. The jet diameter behind the tip is approximately $10 \mathrm{~mm}$. (b) Same exposure taken 6.7 usec later. Note the texture change of the jet surface as it begins to stretch, the ablated copper, and the turbulent shock waves in the air behind the tip. The jet diameter is now about $6 \mathrm{~mm}$. 


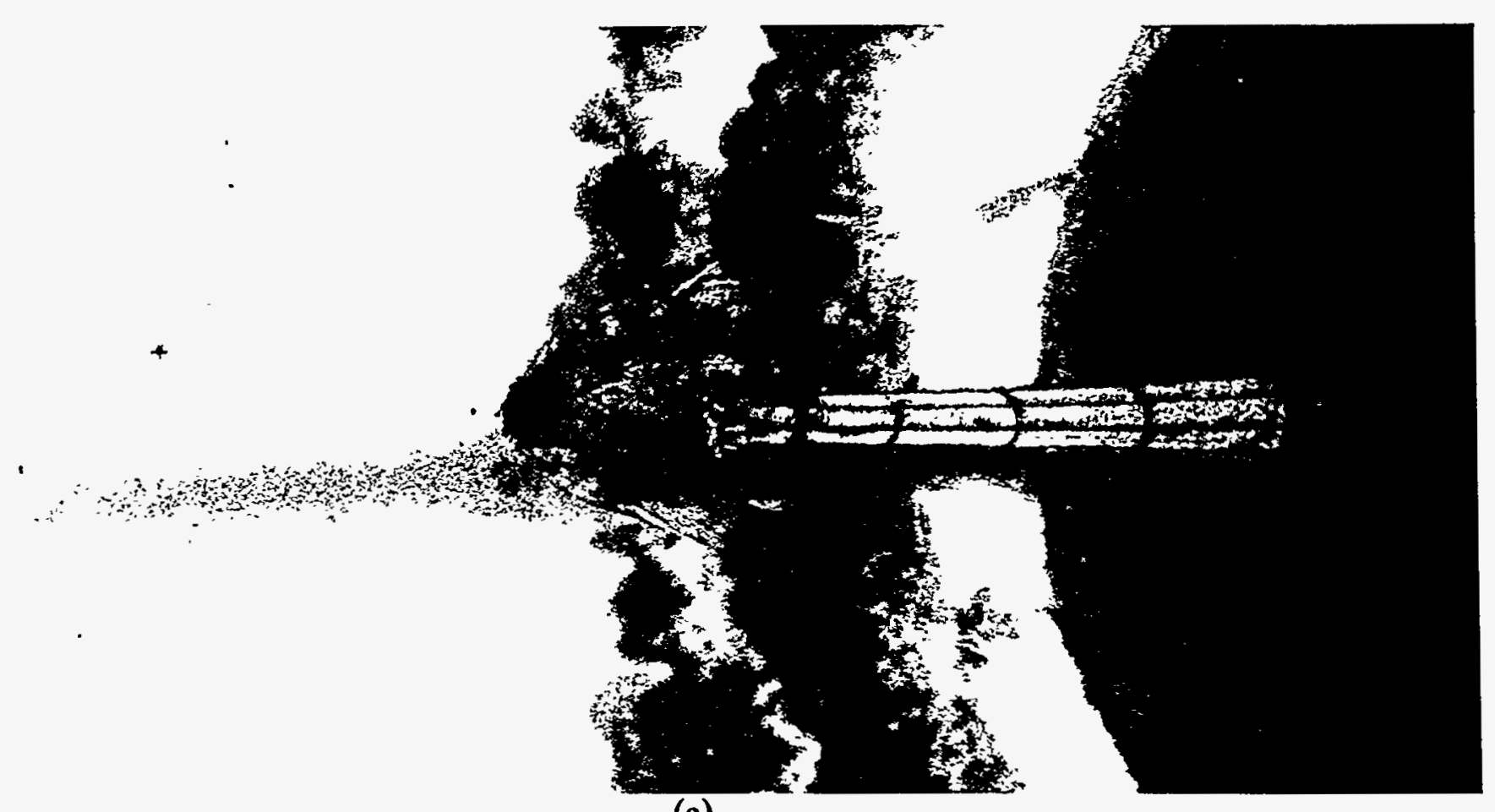

(a)

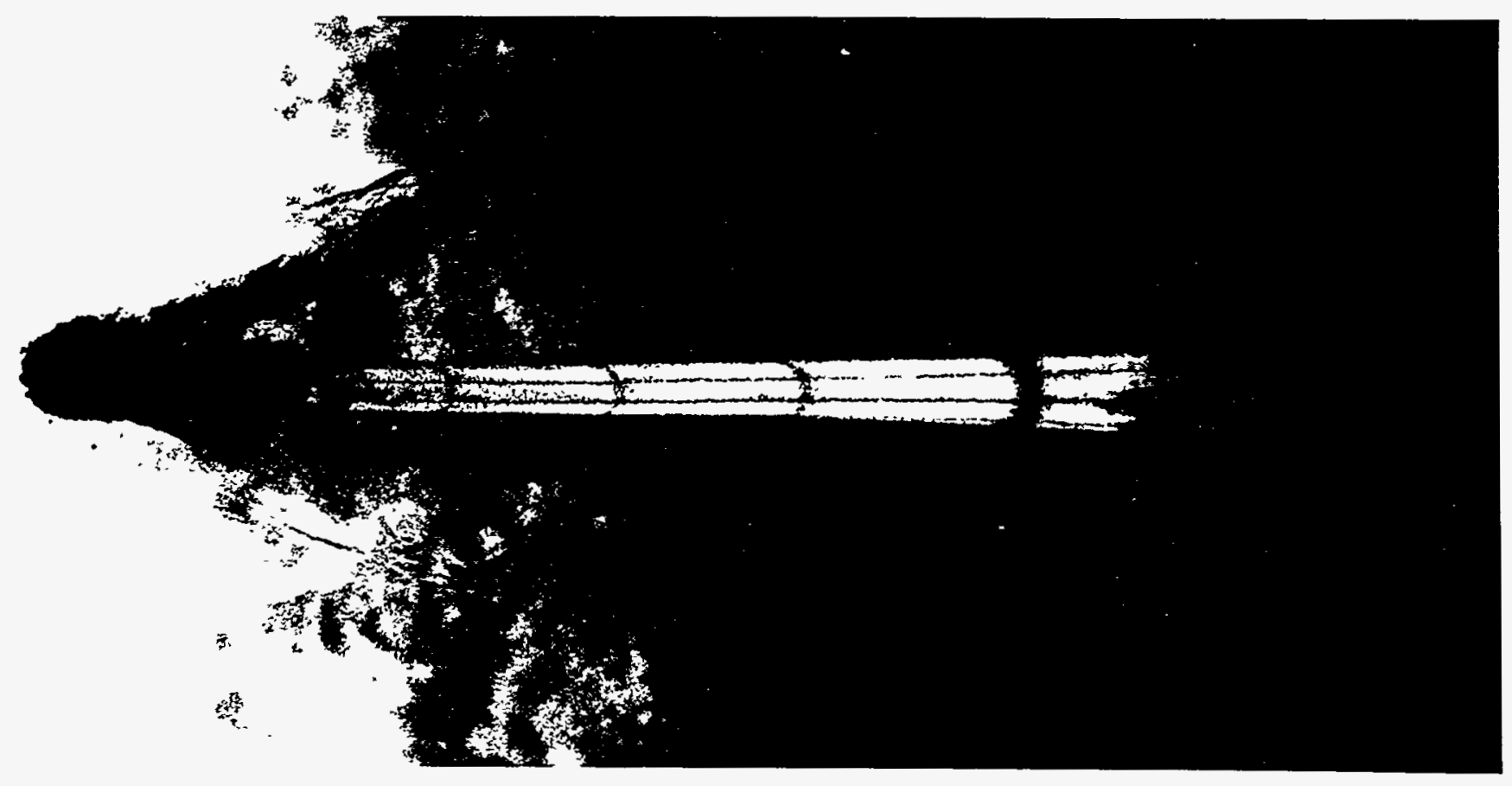

(b)

Figure 7. These IC photographs of the same type of shaped charge as shown in Fig. 6 . The two photographs were taken 10.0 usec apart. The jets tips extend out from the base of the conical liner by approximately (a) 150 and (b) $235 \mathrm{~mm}$. A total of eight photographs were taken of this experiment, and were used to verify that the fabrication technique used for this liner imparts a spin to the resultant jet. An examination of the ink lines along the jet axis show the rotation as the liner collapses and the jet forms. 
The particulating jets shown in Figures 8 and 9 are of unique and recent interest. Particulated jet fragments had previously been observed only in silhouette with low energy pulsed radiography and occasional rotating mirror framing photography. The IC camera photographs show surface crazing and stretching not previously observable. Noted, and not unexpected, are slip dislocation lines running at 45 degrees with respect to the jet axis (Figure 8 ). The similarity to solid metal rods undergoing static tension lead to the conclusion that the Viper jet surface is solid rather than liquid. Totally surprising, however, is the fact that the IC camera pictures show the particulated segments to be connected by highly reflective threads where the radiographs show clear gaps (Figure 9). The threads seem to be liquid copper that are radiographically transparent. Since the physical state of the metal is critical to the understanding and computer modeling of these jets, current efforts are being directed towards dynamic measurements of the temperature profiles of the jets in flight.

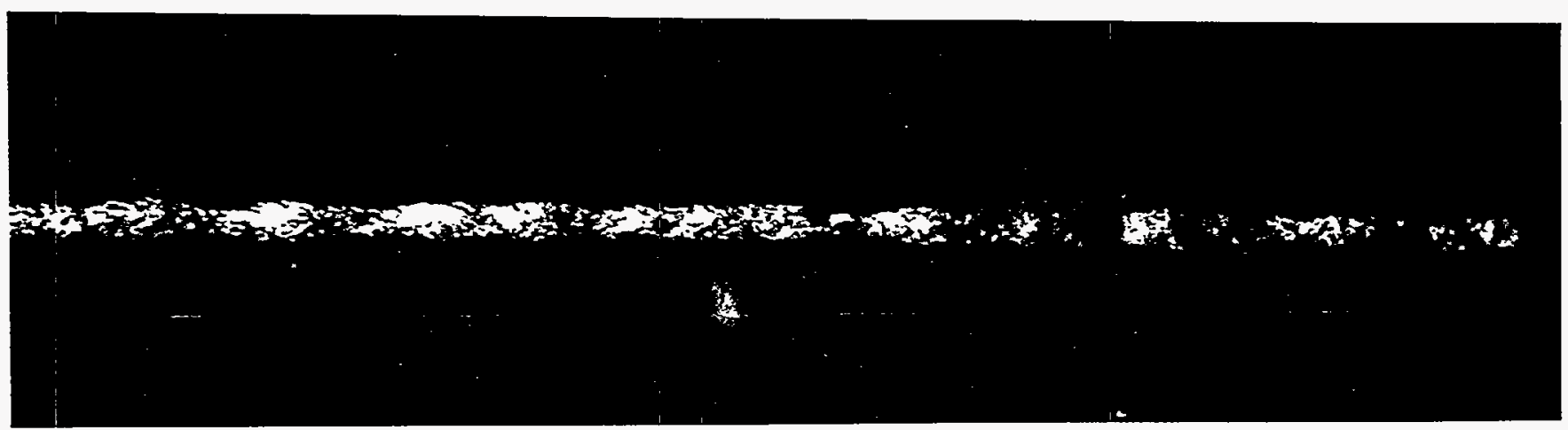

Figure 8. Main body of a jet $320 \mathrm{~mm}$ behind the tip. The jet has travelled $870 \mathrm{~mm}$ from the exit oriface of the shaped charge. The jet tip has a higher velocity than the tail causing the jet to stretch and thin during flight. This jet has a nominal diameter of $1.4 \mathrm{~mm}$ at the time of this photograph, and is beginning to show signs of breaking into separate particles. Note the fine structure on the jet surface including sections that appear crosshatched.

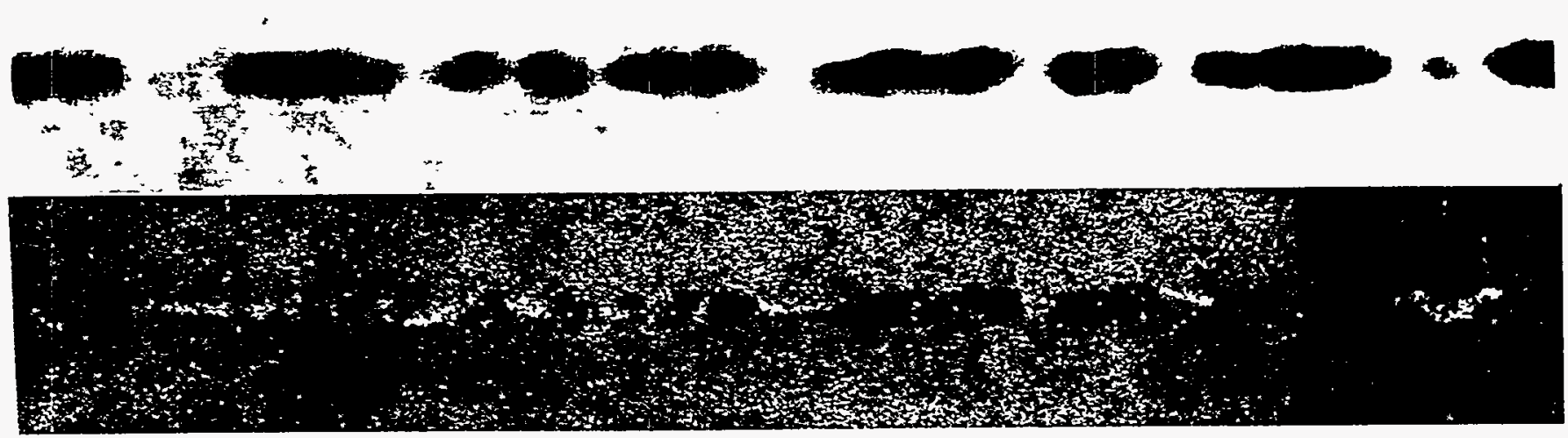

Figure 9. Body of shaped charge jet $200 \mathrm{~mm}$ behind jet tip and approximately $1100 \mathrm{~mm}$ from the exit oriface of the shaped charge. The jet has apparently broken into $2 \mathrm{~mm}$ diameter particles. Above is a section of a 450 $\mathrm{KeV}$ X-ray taken of this jet at the same time as the IC photograph below. Note that the IC photograph clearly shows reflective material between the larger dark particles whereas the radiograph shows little or none. One explanation currently being explored is that there is a thread of liquid copper in the center of the jet that becomes exposed when the jet breaks apart, and that the thread is reflective to the laser illuminator, but too transparent to show in the radiograph. 


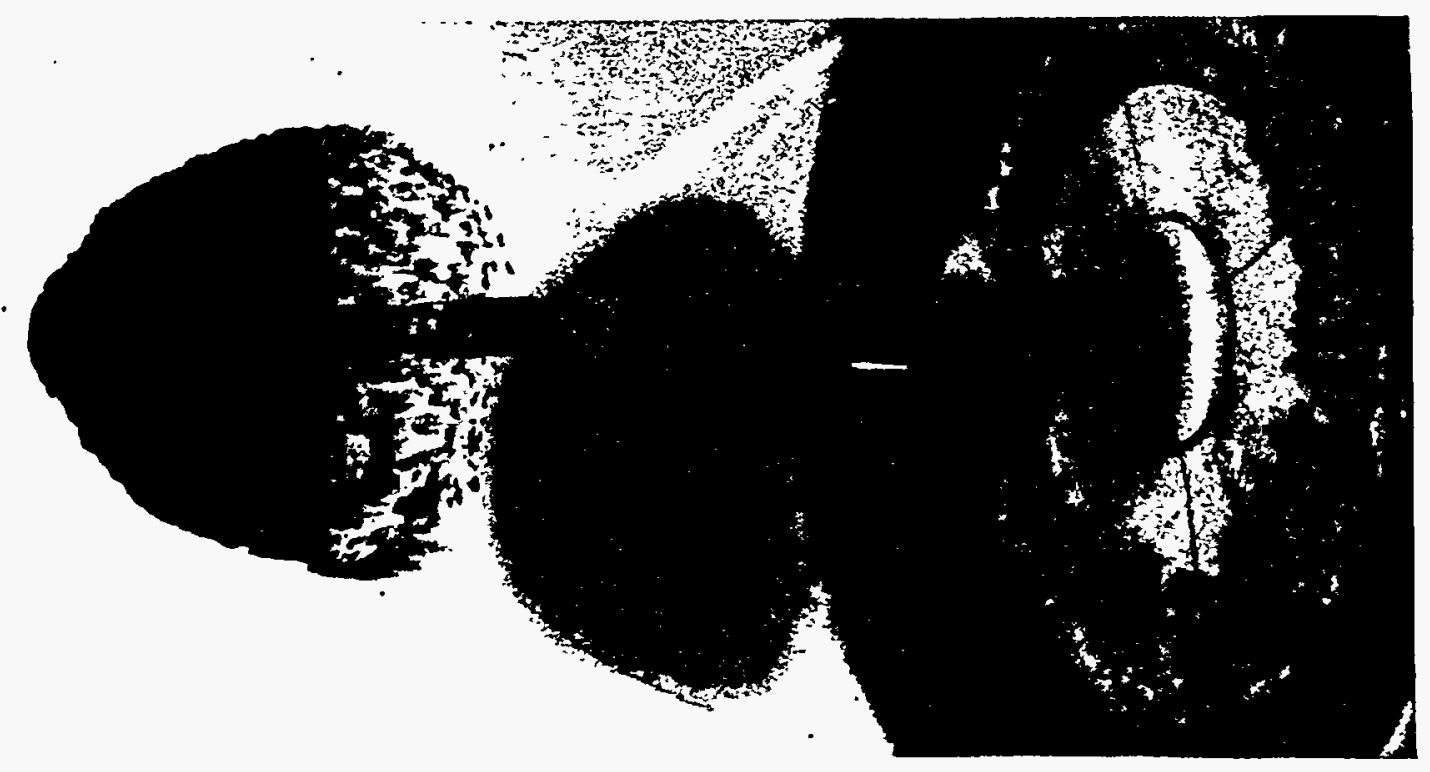

Figure 10. Example of a Viper shaped charge (see Fig. 4) taken when the tip has traveled $80 \mathrm{~mm}$ from the exit oriface (31.5 usec after detonator initiation). Tip velocity is $9.2 \mathrm{~km} / \mathrm{sec}$ creating a clearly visible shock structure in the surrounding air and a shadowgraph on the background surface. The "umbrella" shaped cloud of debris surrounding the tip is a result of ablation and of the rounded apex of the liner cone. The jets shown in Figs. $6 \& 7$ were from larger shaped charges with conical liners having sharp apexes which produce different debris clouds.

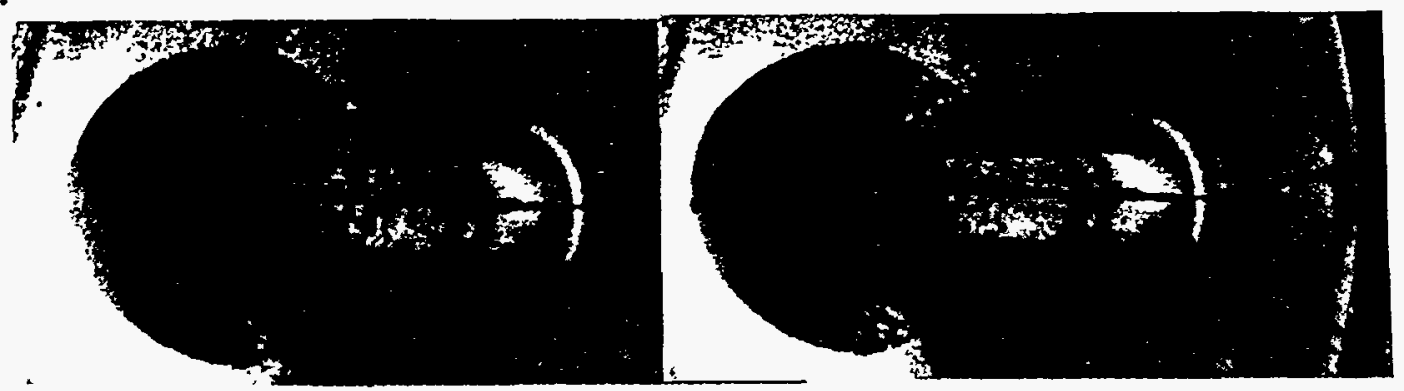

Figure 11. Representative stereo pair of pictures of a Viper taken with the IC camera. To view these images in three dimensions, place the photographs at normal reading distance. Relax your eyes so that you see double images and allow the center two (of the four) to overlap. If you experience difficulty in this free focus technique, try placing a card between the two images from the page towards your nose so that each eye can see only one image. Relax your eyes until the images overlap to see the three dimensional effect.

\section{Conclusions}

The IC camera system provides a unique capability to photograph very fast phenomena such as the metal jets from shaped charge devices. This system provides the resolution to observe the minute surface and metallurgical details of the liner deformation and subsequent jet formation and evolution. It has proven invaluable in providing a detailed picture of the breakup process and surface characteristics during the process of jet particulation. Data from the IC camera pictures has proven indispensable for accurate computer simulations. As was shown in the oral presentation, it also has enhanced the quality of the information obtained from more conventional rotating mirror high speed cameras, viewing the same event, by providing a highly detailed reference when evaluating the data contained in the color frames from these cameras. We continue to improve this system and are currently building the third iteration of the camera that will incorporate a new higher resolution. image converter tube, greatly improved electronics for pulsing the new tubes, and improved objective optics. Because of our desire to emphasize the IC camera system's pictures, we have kept the text to a minimum in this paper. We encourage the reader to review the list of references or contact the authors for more detailed descriptions of the camera system and its applications. 


\section{References}

Baum, D. W., et al. (1992) Application of IC camera with laser illumination to shaped charge metal jet formation. In: Proc. 13th International Symposium on Ballistics. Vol. 2, ADPA, Arlington, VA, USA, pp 575-583

Baum, D. W. et al. (1993) Shaped charge liner collapse and early jet formation. In: Proc. 14th International Symposium on Ballistics, Vol. 2, ADPA, Arlington, VA, USA pp 13-22

Carpluk, G. T. (1970) Laser stereo photography. In: Proc. 9th Internat. Congress on High Speed Photography, SPIE, Bellingham, WA, USA, p 64

Chancel, C., and C. Pelte (1972) Multi-frame image tube camera. In: Proc. 10th Internat., Congress on High Speed Photography, SPIE, Bellingham, WA, USA

Chavailler, C. (1990) High speed photographic systems. In: Proc. 19th Internat. Congress on High Speed Photography, Videography, and Photonics, SPIE 1358, Bellingham, WA, USA, pp 210-226

Jones, P. A. (1974) Four pulse Q-switched ruby laser. J. Phys. E, 7, p 704

Muelder, S. A. et al.(1987) Microchannel plate intensifier version of the IC camera. In: High Speed Photography, Videography, and Photonics V, SPIE 832, Bellingham, WA, USA, pp 57-62

Owren, H. M. (1959) Product bulletin for single frame image converter camera. Abtronics Inc., Livermore, CA, USA

Paisley, D. L. (1976) Laser stereo photography. In: Proc. 12th Internat. Congress on High Speed Photography, SPIE 97, Bellingham, WA, USA, pp 184-188

Parker, Vance C. and Crews, J. L. (1987) Laser shadowgraphs with a rotating mirror camera. In: High Speed Photography, Videography, and Photonics V, SPIE 832, Bellingham, WA, USA, pp 88-95

Shaw, L. L. et al. (1979) $70 \mathrm{~mm}$ format rotating mirror framing camera. In: Proc. 13th Internat. Congress on High Speed Photography, Videography and Photonics, SPIE 189, Bellingham, WA, USA, pp 218-221

Shaw, L. L. et al. (1984) Eight frame electro-optic camera with laser illumination. In: Proc. 16th Internat. Congress on High Speed Photography, SPIE 491, Bellingham, WA, USA, pp 267-273

Shaw, L. L. et al. (1993) Continuing evaluation of shaped charge metal jet characteristics using multi-frame electro-optic camera with laser illumination. In: Proc. 20th International Congress on High Speed Photography, SPIE 1801, Bellingham, WA, USA, pp 92-105

Winer, K. A. et al. (1993) Comparison of dynamic behavior of a shear-formed shaped charge liner to computer simulations. In: Propellants, Explosives, Pyrotechnics, 18, Weinheim, Germany, pp 345-351

Winer, K. A. et. al. (1995) High speed, high resolution observations of shaped charge metal jets undergoing particulation. In: Proc. 15th International Symposium on Ballistics, ADPA, Arlington, VA, USA, pp 89-96

\section{Acknowledgment}

The authors acknowledge the programmatic support of LLNL's B-Division, the technical expertise on the experiments of $\mathrm{R}$. Don Breithaupt, the leadership in shaped charge technology of Dennis W. Baum, Leonard C. Haselman Jr., Christian Simonson III, and Kris Winer of the Advanced Conventional Weapons Program in B-Division, and the technical staff of Bunkers 851 and 801 at LLNL Site 300. The authors extend a special acknowledgment to Anthony T. Rivera, James T. Wade, and James L. Dunmire for their outstanding contributions to the IC camera system fabrication, maintenance and use.

Work performed under the auspices of the U.S.Department of Energy by the University of California, Lawrence Livermore National Laboratory under contract W-7405-Eng-48. This work was supported in part by the Office of Munitions, U.S.Department of Defense, Washington, D.C. 